\title{
Association between Venous Angioarchitectural Features of Sporadic Brain Arteriovenous Malformations and Intracranial Hemorrhage
}

\author{
M.D. Alexander, D.L. Cooke, J. Nelson, D.E. Guo, C.F. Dowd, R.T. Higashida, V.V. Halbach, M.T. Lawton, H. Kim, and S.W. Hetts
}

\begin{abstract}
BACKGROUND AND PURPOSE: Intracranial hemorrhage is the most serious outcome for brain arteriovenous malformations. This study examines associations between venous characteristics of these lesions and intracranial hemorrhage.
\end{abstract}

MATERIALS AND METHODS: Statistical analysis was performed on a prospectively maintained data base of brain AVMs evaluated at an academic medical center. DSA, CT, and MR imaging studies were evaluated to classify lesion side, drainage pattern, venous stenosis, number of draining veins, venous ectasia, and venous reflux. Logistic regression analyses were performed to identify the association of these angiographic features with intracranial hemorrhage of any age at initial presentation.

RESULTS: Exclusively deep drainage (OR, 3.42; 95\% Cl, 1.87-6.26; $P<.001$ ) and a single draining vein (OR, 1.98; 95\% Cl, 1.26-3.08; $P=.002$ ) were associated with hemorrhage, whereas venous ectasia $(\mathrm{OR}, 0.52 ; 95 \% \mathrm{Cl}, 0.34-0.78 ; P=.002)$ was inversely associated with hemorrhage.

CONCLUSIONS: Analysis of venous characteristics of brain AVMs may help determine their prognosis and thereby identify lesions most appropriate for treatment.

A

rteriovenous malformations are complex lesions that have variable clinical presentations and prognoses. The most serious clinical manifestation is intracranial hemorrhage. As such, identification of patients and their respective lesion characteristics can help target higher risk lesions for which treatment is most appropriate. The role of venous features in relation to hemorrhagic propensity is incompletely understood. The current study examines the associations among angiographic features of venous components of arteriovenous malformations and presentation with intracranial hemorrhage in a large prospectively maintained cohort.

Received July 16, 2014; accepted after revision October 21.

From the Department of Radiology (M.D.A.), University of Washington, Seattle, Washington; and Center for Cerebrovascular Research, Department of Anesthesia and Perioperative Care (J.N., D.E.G., H.K.), Department of Radiology and Biomedical Imaging (D.L.C., C.F.D., R.T.H., V.V.H., S.W.H.), and Department of Neurological Surgery (M.T.L.), University of California, San Francisco, San Francisco, California.

This work was supported, in part, by the National Institutes of Health grant R01 NS034949 to H. Kim.

H. Kim and S.W. Hetts contributed equally to this work.

Please address correspondence to Steven W. Hetts, MD, Neurointerventional

Radiology, University of California, San Francisco, 505 Parnassus Ave, L-352,

San Francisco, CA 94143; e-mail: steven.hetts@ucsf.edu

- Indicates open access to non-subscribers at www.ajnr.org

http://dx.doi.org/10.3174/ajnr.A4224

\section{MATERIALS AND METHODS}

The University of California, San Francisco Brain AVM Project data base is a human research protocol-approved, prospectively maintained resource that collects demographic, clinical, and imaging data for patients diagnosed with arteriovenous malformations who were evaluated and treated at this institution. This data base was queried to identify patients with nidal AVMs enrolled between January 2001 and February 2014. Patients with incomplete angiographic records or angiographic characteristics measured after partial treatment were excluded. Additionally, patients with vein of Galen malformations, dural arteriovenous fistulas, non-Galenic pial arteriovenous fistulas, or a hereditary hemorrhagic telangiectasia diagnosis were excluded.

For each patient, the earliest cerebral DSA examination was evaluated by neurointerventional radiologists (S.W.H., D.L.C., C.F.D., R.T.H., V.V.H.), and angioarchitectural features were scored according to a structured format based on recommendations from the Joint Writing Group. ${ }^{1}$ All patients with an AVM underwent 2D digital subtraction angiography performed at fast film rates. Initial CT and MR imaging were also examined by a neurointerventional radiologist to identify any current or prior intracranial hemorrhage.

General demographic variables were noted. Venous compartment features recorded included lesion side (right, left, midline), drainage pattern (exclusively deep, not exclusively deep), degree of venous stenosis $(0 \%-24 \%, 25 \%-49 \%, 50 \%-74 \%, 75 \%-99 \%$, 
Table 1: Summary statistics of AVM cases $^{\mathrm{a}}$

\begin{tabular}{|c|c|c|c|}
\hline \multirow[b]{2}{*}{ Characteristic } & \multicolumn{2}{|c|}{ Hemorrhage on Noninvasive Imaging } & \multirow[b]{2}{*}{ Overall $(n=519)$} \\
\hline & $\begin{array}{c}\text { Nonhemorrhagic } \\
(n=293[56 \%])\end{array}$ & $\begin{array}{l}\text { Hemorrhagic } \\
(n=226[44 \%])\end{array}$ & \\
\hline Age at diagnosis (yr) & $36.9 \pm 17.2$ & $33.5 \pm 19.0$ & $35.4 \pm 18.0$ \\
\hline \multicolumn{4}{|l|}{ Sex } \\
\hline Female & $155(53)$ & $116(51)$ & $271(52)$ \\
\hline Male & $138(47)$ & $110(49)$ & $248(48)$ \\
\hline \multicolumn{4}{|l|}{ White ${ }^{b}$} \\
\hline Yes & $170(58)$ & $113(50)$ & $283(55)$ \\
\hline No & $123(42)$ & $113(50)$ & $236(45)$ \\
\hline \multicolumn{4}{|l|}{ AVM side } \\
\hline Right & $135(46)$ & $105(46)$ & $240(46)$ \\
\hline Left & $146(50)$ & $105(46)$ & $251(48)$ \\
\hline Midline & $12(4)$ & $16(7)$ & $28(5)$ \\
\hline Maximum dimension $(\mathrm{cm})$ & $3.28 \pm 1.58$ & $2.43 \pm 1.55$ & $2.92 \pm 1.62$ \\
\hline \multicolumn{4}{|l|}{ Venous drainage } \\
\hline Not exclusively deep & $275(94)$ & $163(72)$ & $438(84)$ \\
\hline Exclusively deep & $18(6)$ & $63(28)$ & $81(16)$ \\
\hline \multicolumn{4}{|l|}{ Venous stenosis } \\
\hline $0 \%-24 \%$ & $125(43)$ & $112(50)$ & $237(46)$ \\
\hline $25 \%-49 \%$ & $54(18)$ & 38 (17) & $92(18)$ \\
\hline $50 \%-74 \%$ & $73(25)$ & 38 (17) & 111 (21) \\
\hline $75 \%-99 \%$ & 34 (12) & 30 (13) & $64(12)$ \\
\hline $100 \%$ (occlusion) & $7(2)$ & $8(4)$ & $15(3)$ \\
\hline \multicolumn{4}{|l|}{ Number of draining veins } \\
\hline Single & 71 (24\%) & 123 (54\%) & 194 (37\%) \\
\hline Multiple & $222(76 \%)$ & 103 (46\%) & $325(63 \%)$ \\
\hline \multicolumn{4}{|l|}{ Venous ectasia } \\
\hline Yes & $170(58)$ & $76(34)$ & $246(47)$ \\
\hline No & $123(42)$ & $150(66)$ & $273(53)$ \\
\hline \multicolumn{4}{|l|}{ Venous reflux } \\
\hline Yes & $105(36)$ & $46(20)$ & $151(29)$ \\
\hline No & 188 (64) & $180(80)$ & 368 (71) \\
\hline
\end{tabular}

a Values are No. (\%) or mean \pm SD.

${ }^{b}$ Ethnicity is included as a variable, as other studies have shown statistically significant differences in the rates of AVM hemorrhage in individuals of different ethnic backgrounds.

occlusion), number of draining veins (single, multiple), presence or absence of venous ectasia, and presence or absence of venous reflux. Venous stenosis was measured as the narrowest diameter divided by the most proximal measureable portion of the vein. Occlusion was noted if a blind-ending vein was visualized exiting the lesion. To identify factors associated with the presence or absence of intracranial hemorrhage at initial presentation, we performed univariable and multivariable logistic regression analyses, generating odds ratios and 95\% confidence intervals. Variables that were statistically significant $(P<.05)$ in univariable analysis were included in the multivariable analysis to assess which venous compartment features were significant independent predictors of hemorrhagic presentation. All analyses were performed by using STATA/SE 12.0 (StataCorp, College Station, Texas). ${ }^{2}$

\section{RESULTS}

Five hundred nineteen patients were evaluated during the study period. Patient demographics and lesion characteristics are summarized in Table 1. Two hundred twenty-six (43.5\%) patients had intracranial hemorrhage identified on noninvasive imaging. Univariable logistic regression analysis identified exclusively deep venous drainage (OR, 5.90; $P<.001)$ and a single draining vein (OR, 3.73; $P<.001)$ as associated with presentation with intracranial hemorrhage. Age at diagnosis per decade (OR, 0.90; $P=$ .036), AVM size per centimeter (OR, 0.69; $P<.001)$, the presence of venous ectasia (OR, $0.37 ; P<.001)$, and the presence of venous reflux (OR, 0.46; $P<$.001) were inversely related to hemorrhagic presentation. No statistical significance was observed for biologic sex, AVM side, or venous stenosis.

A multivariable logistic regression analysis was performed to evaluate characteristics that were statistically significant in the univariable analysis (results presented in Table 2). Exclusively deep venous drainage remained the most strongly predictive characteristic for intracranial hemorrhage (OR, 3.42; 95\% CI, 1.87-6.26; $P<.001)$. A single draining vein (OR, 1.98; 95\% CI, 1.26-3.08; $P=.002)$, venous ectasia (OR, 0.52; 95\% CI, 0.34-0.78; $P=.002)$, and size (OR, 0.85; 95\% CI, 0.74-0.98; $P=.025$ ) also retained statistical significance. Age at diagnosis $(P=.212)$ and venous reflux $(P=.798)$ became nonsignificant in the multivariable model.

\section{DISCUSSION}

Intracranial hemorrhage accounts for most of the morbidity and mortality caused by brain AVMs. Natural history studies have reported markedly different hemorrhage rates, ranging from $1 \%$ to $34 \%$ risk of rupture, with multiple previously identified risk factors affecting these rates. ${ }^{3}$ Among these, numerous angiographic characteristics of the venous components of these malformations have been noted to affect hemorrhage risk. While certain trends have been identified, disparate results have been reported concerning several venous features. The current study seeks to clarify the role of such venous characteristics by examining a large prospectively maintained series of patients that have been uniformly evaluated on the basis of consensus recommendations. ${ }^{1}$

Deep venous drainage is the single characteristic most frequently associated with AVM hemorrhage. ${ }^{4-8}$ The current study supports this widely reported finding, with exclusively deep drainage more commonly associated with hemorrhage than exclusively superficial or mixed superficial and deep venous drainage. This was the strongest predictor noted in this study. Of note, the subgroup of AVMs in our cohort with superficial nidus location and exclusively deep venous drainage (perhaps implying occlusion of previously extant superficial veins) had a particularly high frequency of hemorrhagic presentation (OR, 9.12; $P=.002)$.

AVMs with fewer draining veins have shown higher rates of hemorrhage in prior studies. ${ }^{9-17}$ Analysis has varied, with some studies looking at correlations of numbers of draining veins ${ }^{14-17}$ and other studies categorizing or dichotomizing numbers to compare hemorrhagic risks. ${ }^{9-13}$ The current study found that lesions with a single draining vein were more likely to be associated with hemorrhage at the time of initial clinical presentation. This find- 
Table 2: Logistic regression analysis (intracranical hemorrhage on presentation as outcome)

\begin{tabular}{|c|c|c|c|c|c|c|}
\hline \multirow[b]{2}{*}{ Characteristic } & \multicolumn{3}{|c|}{ Univariable $(n=519)$} & \multicolumn{3}{|c|}{ Multivariable $(n=519)$} \\
\hline & OR & $95 \% \mathrm{Cl}$ & $P$ Value & OR & $95 \% \mathrm{Cl}$ & $P$ Value \\
\hline Age at diagnosis (decade) & 0.90 & $(0.82-0.99)$ & .036 & 0.93 & $(0.84-1.04)$ & .212 \\
\hline AVM size $(\mathrm{cm})$ & 0.69 & $(0.61-0.79)$ & $<.001$ & 0.85 & $(0.74-0.98)$ & .025 \\
\hline Exclusively deep venous drainage & 5.90 & (3.38-10.32) & $<.001$ & 3.42 & $(1.87-6.26)$ & $<.001$ \\
\hline Single draining vein & 3.73 & $(2.57-5.43)$ & $<.001$ & 1.98 & $(1.26-3.08)$ & .002 \\
\hline Venous ectasia & 0.37 & $(0.26-0.53)$ & $<.001$ & 0.52 & $(0.34-0.78)$ & .002 \\
\hline Venous reflux & 0.46 & $(0.31-0.68)$ & $<.001$ & 0.94 & $(0.59-1.49)$ & .798 \\
\hline Female sex & 0.94 & $(0.66-1.33)$ & .722 & - & - & - \\
\hline White $^{a}$ & 0.72 & $(0.51-1.03)$ & .069 & - & - & - \\
\hline \multicolumn{7}{|l|}{ AVM side ${ }^{b}$} \\
\hline Left & 0.92 & (0.65-1.32) & .668 & - & - & - \\
\hline Middle & 1.71 & $(0.78-3.78)$ & .182 & - & - & - \\
\hline Venous stenosis $^{c}$ & 0.94 & $(0.81-1.09)$ & .436 & - & - & - \\
\hline
\end{tabular}

Note:- - indicates variables that did not show significance on univariable analysis and were not subjected to multivariable analysis.

${ }^{a}$ Ethnicity is included as a variable, as other studies have shown statistically significant differences in the rates of AVM hemorrhage in individuals of different ethnic backgrounds.

${ }^{\mathrm{b}}$ Right side considered baseline; test results comparing either left or right to middle were not significant $(P=.140)$.

${ }^{c}$ Tested using ordinal 5-point scale.

ing has face validity: Fewer draining veins mean fewer potential routes for egress of blood from an AVM, thus presumably increasing the likelihood of AVM pressurization and rupture when any given draining vein thromboses.

Venous ectasia has been examined in previous studies, and there is no consensus on the role of ectasia and the risk of hemorrhage. Some studies report increased risk of hemorrhage, ${ }^{8,13,18,19}$ while other reports suggest no impact ${ }^{12}$ or a protective role for ectasia. ${ }^{11,20}$ This study found that venous ectasia is inversely related to intracerebral hemorrhage. This finding may reflect an adaptive mechanism whereby such dysmorphism supports either a greater efferent capacitance and/or more functional arterialization of the draining veins. Venous ectasia also appears to develop with time, with older patients more likely to demonstrate this feature than younger patients in our cohort. ${ }^{21}$ In our cohort, exceedingly few patients with ectasia have experienced repeat hemorrhage; we have described one of these patients elsewhere. ${ }^{22}$

Similar to ectasia, stenosis or occlusion of draining veins has been examined in prior studies with no resulting consensus. Some studies report increased risk of hemorrhage, ${ }^{4,9,18,20,23,24}$ while other reports suggest no independent effect. ${ }^{11,12,25}$ Venous stenosis offered no predictive value in the current study. Of course, cerebral veins that are completely thrombosed are not directly visible on DSA and only inconsistently identifiable on CT and MR imaging, thus limiting the utility of this measure.

Venous reflux is a less commonly discussed finding but has been suggested to identify lesions more likely to cause hemorrhage, presumably because reflux is an indicator of increased venous pressure. ${ }^{18,26}$ However, venous reflux was inversely related to hemorrhage in univariable analysis in this study. This association did not persist in the multivariable model, suggesting interaction with other variables.

When considering numerous characteristics, there is potential for confounding variables. For example, multiple series have shown that smaller AVMs are more likely to bleed. However, small AVMs are also likely to have fewer draining veins, which also carry an increased association with hemorrhagic risk. Similarly, central lesions are more likely to rupture, but these lesions are also more likely to have deep draining veins. In the current analysis, age at diagnosis and the presence of venous reflux demonstrated statistical significance in univariable analysis, but their roles were not confirmed in the multivariable analysis. Size persisted as a significant predictor of intracerebral hemorrhage in multivariable analysis, though to a lesser degree than singular venous outflow or deep venous drainage.

While this study identifies an association of venous architectural features with intracranial hemorrhage, it has several limitations. This was a cross-sectional analysis of prospectively enrolled patients in a robustly designed data base, but it examined an outcome that occurred contemporaneously with or before enrollment. Hemorrhagic association was based solely on imaging features and did not account for clinical features. Furthermore, analysis allowed by this database did not permit differentiation between hemorrhage occurring acutely at the time of enrollment or evidence of prior hemorrhage noted on noninvasive imaging at the time of enrollment. Additionally, the analysis does not distinguish the hemorrhagic location (eg, intraparenchymal versus intraventricular). Furthermore, it is possible that hemorrhage may alter angioarchitectural features in such a way that they differ from what would be identified before the hemorrhage.

Further investigation is warranted for both clinical and angiographic features that can predict AVM hemorrhage, to most accurately stratify hemorrhagic risk and thereby identify patients most suitable for treatment. This is particularly important because of the publication of the A Randomized Trial of Unruptured Brain Arteriovenous Malformations study, ${ }^{27}$ wherein a relatively short follow-up of previously unruptured AVMs demonstrated inferior outcomes for patients who received therapeutic interventions compared with patients who received conservative medical follow-up.

\section{CONCLUSIONS}

Venous factors appear to influence the likelihood that arteriovenous malformations will present with hemorrhage. Exclusively deep venous drainage and a single draining vein were associated with hemorrhage presentation, while venous ectasia was inversely associated with this presentation. Age at diagnosis and venous reflux did not retain statistical significance in a multivariable model. Venous characteristics should be considered when evaluating AVMs and predicting their natural history, thus helping to determine which lesions may be most appropriate for treatment.

\section{ACKNOWLEDGMENTS}

The authors wish to acknowledge the contributions of William L. Young, MD, to AVM research in general and to this study in particular. Dr Young was the Founder and Director of the University of California, San Francisco Center for Cerebrovas- 
cular Research before his untimely death. The authors also wish to thank Voltaire Gungab for assistance in manuscript preparation.

Disclosures: Jeffrey Nelson—RELATED: Grant: received salary support from National Institutes of Health grant NS034949.* Diana E. Guo-RELATED: Grant: National Institutes of Health (R01 NS034949), ${ }^{*}$ Comments: This grant is paid to Helen Kim, Center for Cerebrovascular Research. Christopher F. Dowd-UNRELATED: Other: MicroVention, Comments: Chief Adjudicator, Flow Re-direction Endoluminal Device trial. Helen Kim—RELATED: Grant: receives salary support from the National Institutes of Health grant R01 NS034949*; UNRELATED: Travel/Accommodations/Meeting Expenses Unrelated to Activities Listed: receive travel reimbursements from National Institutes of Health grant R01 NS034949 when presenting AVM research at conferences/meetings. Steven W. Hetts-RELATED: Grant: National Institutes of Health-National Institute of Neurological Disorders and Stroke, ${ }^{*}$ Comments: brain AVM study funding to Helen Kim and the University of California, San Francisco, Center for Cerebrovascular Research; UNRELATED: Consultancy: Medina Medical, Silk Road Medical, Comments: consulting on medical device design. *Money paid to the institution.

\section{REFERENCES}

1. Atkinson RP, Awad IA, Batjer HH, et al. Reporting terminology for brain arteriovenous malformation clinical and radiographic features for use in clinical trials. Stroke 2001;32:1430-42

2. StataCorp. 2011 Stata Statistical Software: Release 12. College Station: StataCorp LP

3. Rutledge WC, Ko NU, Lawton MT, et al. Hemorrhage rates and risk factors in the natural history course of brain arteriovenous malformations. Transl Stroke Res 2014;5:538-42

4. Willinsky R, Lasjaunias $\mathrm{P}$, Terbrugge $\mathrm{K}$, et al. Brain arteriovenous malformations: analysis of the angio-architecture in relationship to hemorrhage (based on 152 patients explored and/or treated at the hopital de Bicêtre between 1981 and 1986). J Neuroradiol 1988;15:225-37

5. Duong DH, Young WL, Vang MC, et al. Feeding artery pressure and venous drainage pattern are primary determinants of hemorrhage from cerebral arteriovenous malformations. Stroke 1998; 29:1167-76

6. Langer DJ, Lasner TM, Hurst RW, et al. Hypertension, small size, and deep venous drainage are associated with risk of hemorrhagic presentation of cerebral arteriovenous malformations. Neurosurgery 1998;42:481-86; discussion 487-89

7. Miyasaka $\mathrm{Y}$, Kurata $\mathrm{A}$, Irikura $\mathrm{K}$, et al. The influence of vascular pressure and angiographic characteristics on haemorrhage from arteriovenous malformations. Acta Neurochir (Wien) 2000;142: $39-43$

8. Stefani MA, Porter PJ, terBrugge KG, et al. Angioarchitectural factors present in brain arteriovenous malformations associated with hemorrhagic presentation. Stroke 2002;33:920-24

9. Miyasaka Y, Yada K, Ohwada T, et al. An analysis of the venous drainage system as a factor in hemorrhage from arteriovenous malformations. J Neurosurg 1992;76:239-43

10. Albert $P$, Salgado H, Polaina M, et al. A study on the venous drainage of 150 cerebral arteriovenous malformations as related to haemor- rhagic risks and size of the lesion. Acta Neurochir (Wien) 1990; 103:30-34

11. Kubalek R, Yin L, Fronhöfer G, et al. Cerebral arterio-venous malformations: correlation between the angioarchitecture and the bleeding risk [in German]. Klin Neuroradiol 2001;11:97-104

12. Kubalek R, Moghtaderi A, Klisch J, et al. Cerebral arteriovenous malformations: influence of angioarchitecture on bleeding risk. Acta Neurochir (Wien) 2003;145:1045-52; discussion 1052

13. Lv X, Wu Z, Jiang C, et al. Angioarchitectural characteristics of brain arteriovenous malformations with and without hemorrhage. World Neurosurg 2011;76:95-99

14. Albert P. Personal experience in the treatment of 178 cases of arteriovenous malformations of the brain. Acta Neurochir (Wien) 1982;61:207-26

15. Pollock BE, Flickinger JC. A proposed radiosurgery-based grading system for arteriovenous malformations. J Neurosurg 2002;96: 79-85

16. Ji Y, Ding X, Wang ZG. Analysis of relevant factors of cerebral arteriovenous malformation with hemorrhage [in Chinese]. Zhonghua Yi Xue Za Zhi 2012;92:2488-90

17. Niu H, Cao Y, Wang X, et al. Relationships between hemorrhage, angioarchitectural factors and collagen of arteriovenous malformations. Neurosci Bull 2012;28:595-605

18. Nataf F, Meder JF, Roux FX, et al. Angioarchitecture associated with haemorrhage in cerebral arteriovenous malformations: a prognostic statistical model. Neuroradiology 1997;39:52-58

19. Bai J, Dou CW, Wang YJ, et al. Correlations of angio-architectural factors with cerebral arteriovenous malformation hemorrhage [in Chinese]. Zhonghua Yi Xue Za Zhi 2012;92:2202-04

20. Mansmann U, Meisel J, Brock M, et al. Factors associated with intracranial hemorrhage in cases of cerebral arteriovenous malformation. Neurosurgery 2000;46:272-79

21. Hetts SW, Cooke DL, Nelson J, et al. Influence of patient age on angioarchitecture of brain arteriovenous malformations. AJNR Am J Neuroradiol 2014;35:1376-80

22. Alexander MD, Hetts SW, Young WL, et al. Supernova hemorrhage: obliterative hemorrhage of brain arteriovenous malformations following gamma knife radiosurgery. J Neurointerv Surg 2012;4: 364-67

23. Marks MP, Lane B, Steinberg GK, et al. Hemorrhage in intracerebral arteriovenous malformations: angiographic determinants. Radiology 1990;176:807-13

24. Pasqualin A. Natural history of cerebral AVM [in Italian]. Neuroradiol J 2002;15:29-40

25. Miyasaka Y, Tanaka R, Kurata A, et al. The factors influencing haematoma volume due to arteriovenous malformations. Acta Neurochir 1999;141:385-87; discussion 387-88

26. Lasjaunias P, Manelfe C, Chiu M. Angiographic architecture of intracranial vascular malformations and fistulas-pretherapeutic aspects. Neurosurg Rev 1986;9:253-63

27. Mohr JP, Parides MK, Stapf C, et al; international ARUBA investigators. Medical management with or without interventional therapy for unruptured brain arteriovenous malformations (ARUBA): a multicentre, non-blinded, randomised trial. Lancet 2014;383: $614-21$ 